Review

\title{
Teen Childbearing and Economics: A Short History of a 25-Year Research Love Affair
}

\author{
Saul D. Hoffman \\ Department of Economics, University of Delaware, Newark, DE 19716, USA; \\ E-Mail: hoffmans@udel.edu \\ Academic Editor: Naomi Farber
}

Received: 6 July 2015 / Accepted: 16 September 2015 / Published: 17 September 2015

\begin{abstract}
Despite its apparent distance from the core topics of economics, economists have been attracted to, and deeply engaged in, research about teen fertility for more than a quarter century. Research has focused on two broad, interrelated issues: the socio-economic consequences of a teen birth and the socio-economic causes of a teen birth. In researching these issues, economists have drawn on and extended basic concepts in economic theory and in applied statistical research. I review those literatures for a non-economist audience and conclude that the research love affair has substantially benefited both parties, although definitive answers to causes and consequences are still elusive.
\end{abstract}

Keywords: teen pregnancy; teen births; non-marital births

\section{Introduction}

It is relatively easy, at least for an economist, to see why economists would be attracted to issues like teen pregnancy and teen childbearing, despite their apparent distance from the core topics of economics. First, economics - especially microeconomics — is fundamentally the study of choices that individuals make, traditionally and most often in formal markets with monetary prices, but now more and more frequently outside that sphere. Viewed from that perspective, choices involving sexual and fertility behavior among teens are an incredibly challenging, but inviting, target. Is it possible to identify the role of economic incentives, including government policy, on these behaviors? Is it sensible to apply traditional models of rational choice decision-making to teens?

Second, the traditional concern about teen fertility was predicated on the notion that it was an economically catastrophic act. In a famous and oft-quoted 1968 article, Arthur Campbell wrote that 
"The girl who has an illegitimate child at the age of 16 suddenly has 90 percent of her life's script written for her" [1] (p. 238), including reduced opportunities for schooling, the labor market, and marriage. But it doesn't take too much reflection to appreciate that more may be going on in leading to these poor outcomes than just a teen birth. Disentangling the causal effect of teen childbearing on subsequent socio-economic outcomes from its correlational effect is another deliciously inviting and challenging target, this time well-suited for the applied economist or econometrician.

Just to make all this yet more inviting, the two research strands are closely related. Suppose it could be demonstrated that for some teens the socio-economic impact of a teen birth was negligible. For example, maybe future prospects for some teens were equally poor with or without a birth or perhaps government programs provided substantial benefits, so that the net impact on socio-economic well-being was consequently small or even positive. Then, it might well be "rational" in an economic sense to have a teen birth in the first place, thereby linking the research on the causal impact of a teen birth with the research on the choice determinants of a teen birth. So what came to be known as the teen birth "causes" literature and the teen birth "consequences" literature were clearly interrelated.

And then, to add yet another layer of challenge, the teen fertility rate in the U.S. has fallen at a rate that is totally unprecedented (see Figure 1). Teen fertility was once widespread, with most of it occurring within early and sometimes not entirely voluntary marriage. In 1960, the teen fertility rate was approximately 90 births per 1000, which implied that more than $40 \%$ of women ever had a teen birth. When I published my first article on teen births 25 years ago [2], the teen fertility rate was 60 births per 1000, down one-third from 1960, but it had increased six years in a row in what turned out to be a deviation from the downward trend. Since then the rate has declined every single year, except for a short but puzzling uptick between 2005 and 2007. In 2014, the teen fertility rate was 24.2 births per 1000 , the lowest teen fertility rate every recorded in the U.S., though still shockingly high by European standards [3]. ${ }^{1}$ Thus, the rate fell by more than 50\% during my professional association with the topic and by $70 \%$ since 1960 . Of course, at the same time teen marital births largely disappeared, falling from $85 \%$ of teen births to $12 \%$.

This adds yet another focus for economic research. Why did the rate fall? Did it have anything to do with changes in the costs of teen childbearing or changes in policy? Is it a good thing or not?

In this article I try to make sense out of these various research strands by providing a personal narrative through the economics literature on teen childbearing, with a special emphasis on the three issues discussed above. My goal is to make the literature, including some reasonably technical content, accessible and valuable to a non-economist.

1 In order to focus on broad methodological issues, I do not attempt to explain the higher teen fertility rate in the U.S. Suffice it to say that the U.S. is an outlier and that simple explanations involving public support and transfers cannot be an explanation since most European countries with lower teen fertility have more generous support systems. 


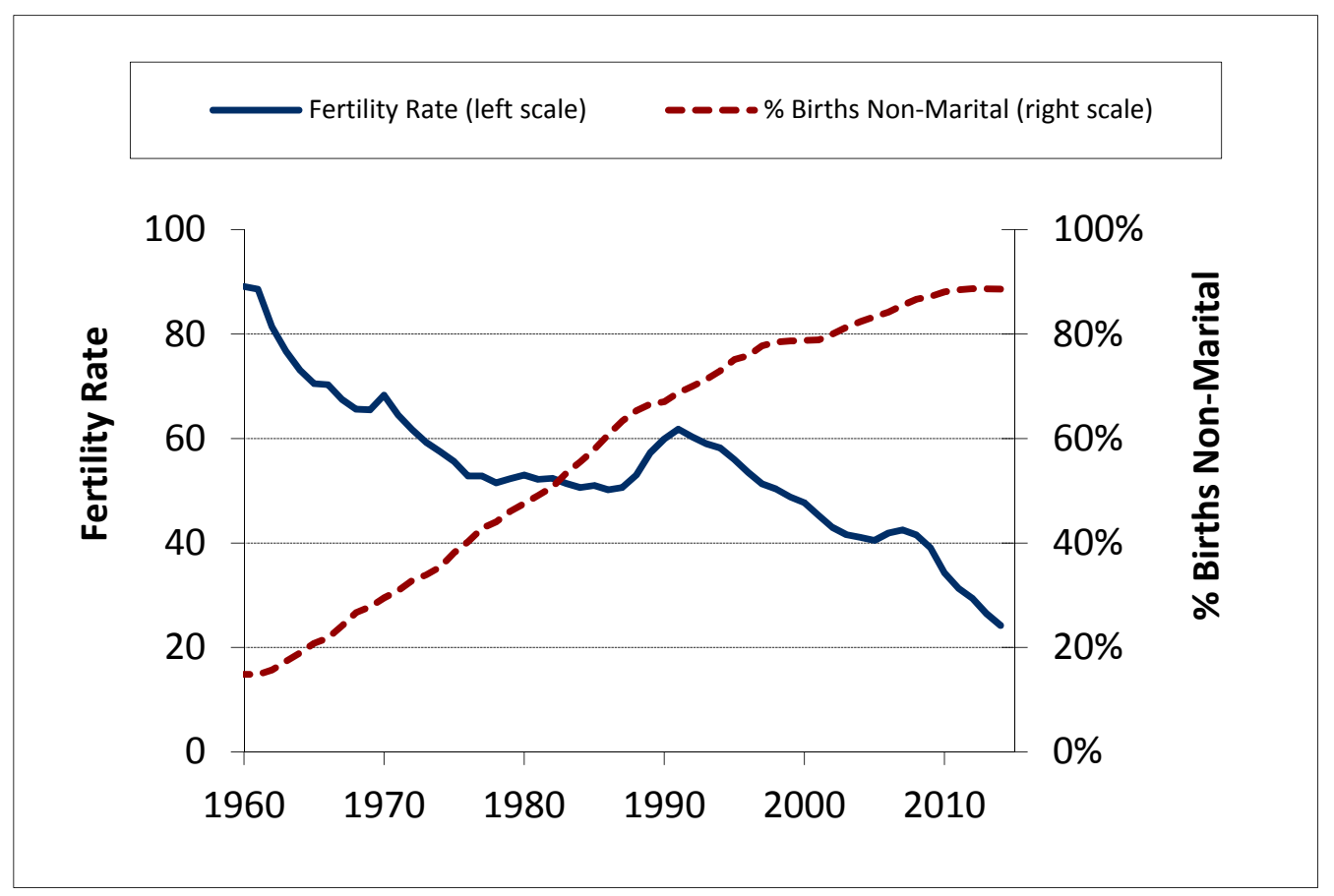

Figure 1. U.S. Teen Fertility, 1960-2014.

\section{The Socio-Economic Consequences of a Teen Birth: Methods and Findings}

Problems. A very lengthy literature in economics and sociology has attempted to measure the socio-economic consequences of a teen birth; for a well-known early survey see Hayes [4] and for well-known more recent ones see Maynard [5] and Hoffman and Maynard [6]. Measuring the socio-economic consequences of a teen birth is orders of magnitude more complicated than it might seem. The first important point to make is that there is no such thing as the socio-economic consequences of a teen birth in the sense of an effect that is independent of time period or geographic location. Policies and countries and cultural context surely matter and these vary over time and space. Just as an illustration, the safety net in the U.S. in the mid-2010s is far different than it was in the 1980 s or 1990s and so too is the labor market for less-educated men and women. As a result, the socio-economic consequences of a teen birth are likely to differ across these time periods. At best, we can hope to measure an average teen birth effect for a particular population living in a particular time and place. The effect on a particular teen mother will naturally vary, some greater, some smaller.

To make matters yet worse, we can only know what the effects of a teen birth have been, not what they likely will be for current teen mothers. If we want to measure the impact over a time span long enough to reflect long term or life-cycle impacts, then inevitably the births in question must have occurred just as long ago in the past, when circumstances and policies were potentially different — exactly as argued above. Are the results of studies like that predictive for contemporary teen births or are they primarily of historical value? The answer is not always obvious and it is almost never acknowledged.

The second equally important point is that even if there were such a thing as the teen birth effect, we could never measure it fully accurately with confidence. Understanding this latter point requires a minor, but relatively painless, detour into statistical analysis. The standard way to quantify the relationship between a potentially causal variable like a teen birth and some outcome like subsequent 
family income is with regression analysis. In the very simplest form, this can be written as $\mathrm{Y}=\beta_{0}+\beta_{1} \mathrm{~TB}+\eta$, where $\mathrm{Y}$ is the outcome of interest (e.g., education, earnings, or poverty status), TB is a measure of whether a young woman had a teen birth ( $=1$ if yes, $=0$ if no), and $\eta$ is a random error term representing all the other factors that may affect outcome $Y$ but are unobserved. Technically, $\beta_{0}$ is the average value of $Y$ for women without a birth, while $\beta_{0}+\beta_{1}$ is the corresponding average $Y$ for women with a teen birth, so that $\beta_{1}$ is the difference in the average $Y$ between the two groups of women. This is the simplest possible formulation imaginable because it includes only a single explanatory variable (TB). In effect, this simple model attributes all the difference in outcome Y between the two groups to the single difference between them in having had (or not) a teen birth.

An immediate and natural criticism is that this model is far too simple, because it fails to account for other factors that affect outcome $Y$. This criticism is both potentially true and false, that is to say, it depends on the particulars of the analytical situation, which, in turn, illuminates why we can never measure the causal effect perfectly. Let's agree that some other variable (call it Z) also affects outcome Y. Z could be mother's education or neighborhood quality or the income of the young woman's family when she was growing up; all of these are firmly established in the research literature in economics and sociology as causal factors affecting adult outcomes. It is clear enough that if $\mathrm{Z}$ is omitted, then $\mathrm{Y}$ will be less fully explained than if it were included; this would be reflected in an $\mathrm{R}^{2}$ value that is lower than it might be. But it is not immediately clear how the estimate of $\beta_{1}$ will be affected. It is, in fact, quite possible, for $\mathrm{Y}$ to be poorly explained, but at the same time for the causal effect of a teen birth to be estimated accurately.

Fortunately, the statistical theory of omitted variable bias tells us exactly how this works out. Without going through the formulas and equations, the key results, which are critical for the entire research literature on teen birth consequences, are as follows. (1) If a variable that affects Y is omitted from a regression equation, it biases the estimates of all variables with which it is correlated. The extent of the bias increases with the size of the correlation between the omitted variable and $\mathrm{X}$ and also with the impact of the omitted variable on the outcome $\mathrm{Y}^{2}$ (2) Omitted variables that are uncorrelated with the causal variable of interest do not create bias, even if they are important determinants of $\mathrm{Y}$.

These two results are actually remarkably intuitive, as well as incredibly useful in a wide range of applications well beyond teen childbearing. If a relevant explanatory factor is omitted, then its effect on Y is "captured" by the included variable to the extent that the two variables are correlated. As such, the estimated effect reflects, at least in part, a correlation, rather than a causal effect. In that case, a policy that managed to reduce the incidence of teen childbearing would have an actual effect different from the estimated effect, unless it also changed the correlated variables. (More on this below.) But if, instead, the omitted variable is uncorrelated with the included variable, then its omission is harmless in so far as determining the causal effect of $\mathrm{X}$ on $\mathrm{Y}$ is concerned.

Based on this, it is possible to see exactly why the critique of the overly simple one-variable model of teen birth effects can be either true or false - and what would have to be done to estimate a causal

2 The bias is the product of these two terms. Because the bias term is multiplicative, it is often possible to predict the sign of the bias. The correlation term is actually the estimated coefficient on the included variable of interest in a regression of the excluded variable on all the included variables. 
estimate of a teen birth. Suppose, for example, that it were possible to run a randomized control trial (RCT) in which the treatment was having a teen birth and young women were randomly assigned to have or not have a birth (Of course, such a trial cannot be conducted, for obvious reasons). In that case, while other factors might well influence the outcome of interest, their omission from the analysis would not affect the estimate of the treatment effect, here, the effect of a teen birth on subsequent socio-economic outcomes. The reason is exactly what makes RCTs the gold standard of research: by construction, the experimental design makes omitted variables uncorrelated with the treatment.

In the absence of an RCT, however, researchers have only data generated by actual human behaviors and choices about fertility, education, marriage and so on. In that case, omitted variables will very likely be correlated with both having a teen birth and the outcome in question.

In the world of social science research about the effects of a teen birth on socio-economic outcomes, no one would dream of estimating the simple one-variable model that I introduced above, precisely because it is obvious that teen births do not occur randomly. Thus, explanatory variables are added: race, ethnicity, family structure, family income, urban residence, parents' education, neighborhood characteristics, and so on, depending on the data source. This was the standard practice in the research literature on teen birth effects through the early 1990s and it was considered good enough. But that was before economists discovered selection bias [7], which compelled social scientists - especially economists - to confront the role of unmeasured and perhaps unmeasurable variables more directly. Truthfully, the potential observable variables available in even the best nationally-representative U.S. samples such as the Panel Study of Income Dynamics (PSID), National Longitudinal Survey of Youth (NLSY) or The National Longitudinal Study of Adolescent to Adult Health Adolescent Health (ADD-Health) are quite limited relative to the ways in which young women differ from one another and that might affect both their likelihood of having a teen birth and their subsequent socio-economic outcomes. No matter how long the list of available explanation variables, it is always possible to argue that some critical variable is yet omitted. And the charge is impossible to rebut fully: on what rigorous basis can a researcher argue that he or she has included all relevant correlated variables? The unhappy result is that these studies are inevitably imperfect, with, even worse, the extent of imperfection (technically, bias) impossible to pin down.

This, in a nutshell, is the basis for my pessimistic statement above that, even if there were a teen birth effect, we could never measure it perfectly. We cannot conduct an RCT and cannot persuasively measure all relevant variables that are correlated with a teen birth and the outcome of interest. Researchers are left estimating an effect that cannot be definitive.

Indeed, it is plausible that any estimate of a teen birth effect on outcomes from standard data sets using standard regression analysis is an over-estimate of the true effect. Adding observable explanatory variables (e.g., the teen mother's education or her own mother's education) to a teen birth regression typically reduces (in absolute value) the estimated teen birth effect, confirming the basic message of omitted variable analysis. By extension, if we could add measures of the unobserved variables, they, too, might operate in the same way to reduce the estimated effect; perhaps teen mothers and non-teen mothers differ in unobservable ways as well that also contribute to the difference 
in outcomes. Since we cannot add these unobservable factors, this implies that the resulting regression estimate is still too large. ${ }^{3}$ It does not follow, of course, that the true effect must be zero.

A Very Very Important Caveat. Suppose that we were attempting to evaluate on a cost/benefit basis a proposed intervention that would potentially reduce the teen birth rate. Conceptually, the benefits of such a program are the negative socio-economic impacts that would be averted. Would the causal impact of a teen birth (if we could measure it) be the appropriate benefit measure to use to evaluate the program?

The answer depends on what the intervention actually does. The causal effect is the impact of a teen birth, with no other changes in a young woman's life prior to the time at which a teen birth or perhaps pregnancy occurs; the young woman is the same, except for her first birth timing and whatever follows directly from the delay in the first birth, such as changes in education, work, and marriage. In terms of policy, this thought experiment might best correspond to an intervention involving the timely distribution of long-acting reversible contraceptives (LARCs) that prevent a pregnancy with substantial certainty but do not otherwise change the particulars of a young woman's life prior to the administration of the LARC; see Peipert et al. [8] and Secura et al. [9] for an evaluation of such an intervention in a slightly different context. But many, if not most, interventions attempt to change something about an adolescent female-her self-image, her school or neighborhood quality, her confidence, her negotiation skills, her after-school activities, and so on - that will affect her early fertility and that may also affect subsequent socio-economic outcomes, independently of the delay of a first birth. In that case, the causal estimate is absolutely the wrong estimate and will typically underestimate the benefits of the intervention.

To make this idea clearer, let's return to the simple one-variable model of the effect of a teen birth introduced at the beginning of this section. It does not provide an estimate of the causal effect of a teen birth on subsequent outcomes. Rather, it is a measure of the potential benefits of a successful intervention that eliminated all pre-existing differences between the average woman who is a teen mother and the average woman who is not. Most interventions would likely eliminate much less than this and thus have fewer benefits. But as long as they eliminate some relevant differences between the two groups of women, they will have benefits greater than the pure causal effect of a teen birth.

Solutions. The major research strands in the teen birth literature make sense when viewed from the perspective of omitted variable problems and in light of the impossibility of conducting a teen birth RCT. They are all attempts to identify circumstances in which omitted and unobserved variables are less likely to be problematic.

Four broad approaches have been used to measure the socio-economic impact of a teen birth (in a specific place and time and for a specific population). Again, I provide an intuitive overview without going through the technical details and formulas. One is adding additional observable independent variables, but that is simply not likely to resolve lingering statistical issues of causality, given what is actually available for inclusion in nationally-representative samples. A second involves comparing outcomes across sisters who differ in their fertility timing. ${ }^{4}$ Quite plausibly, sisters are more alike than

3 This line of argument has the annoying feature that a researcher is often confidently reporting the results of a regression that he/she has not and cannot perform and thus whose results are not really known.

4 Technically, the use of sisters to estimate teen birth effects is an example of a family fixed effects model, an approach widely used in other research contexts as well [10,11]. 
two unrelated women; they share some family background and neighborhood features that are otherwise difficult to measure. As a result, there are fewer unmeasured variables whose correlation with a teen birth and the outcome variable are the root of the problem. Unmeasured individual differences may yet exist and if they are correlated with a teen birth, this would create a potential problem, but probably of a second order of magnitude.

A third approach is to emulate an RCT by identifying a situation in which a teen birth is (more or less) randomly assigned. Such a situation is usually referred to as a "natural experiment." The difference between a natural experiment and an RCT is that a natural experiment occurs without the intervention and design of the researcher. Identifying natural experiments is as much art as science. Examples in the social sciences, especially in economics, abound: differential WWII mobilization rates of men across U.S. states meant that some young women faced more enhanced labor market opportunities than others [12]; anti-obscenity laws dating from the early part of the 20th century were later interpreted in such a way that young women had earlier access to oral contraceptives in some U.S. states than in others [13]; the increase in the minimum wage in New Jersey in 1992 meant that employers of less-skilled workers there had to pay a higher wage than in Pennsylvania, its neighboring state that did not have an increase [14]. In the teen birth case, a miscarriage provides a potential natural experiment [15]. Most miscarriages are random and they result in an arbitrary delay in the onset of early fertility. Thus whether a young woman has a teen birth or has a delay in the timing of her first birth is plausibly uncorrelated with other unmeasured factors that affect the outcomes of interest. More on this below.

The final approach - instrumental variables (IV) or two-stage least squares - is the most technical and least used. The underlying idea is to find some variable, called an instrument, which affects the probability of a teen birth, but does not directly affect the outcome of interest. Policy measures, like access to health clinics, or individual characteristics, like age at menarche that might be a determinant of early sexual activity, are examples of instruments that have been used in this literature ${ }^{5}$. The statistical approach involves using the instrument to predict the probability of a teen birth that varies across young women in a way similar to a natural experiment. The predicted probability then replaces the actual observation of a teen birth in a regression equation to estimate a causal effect.

An exhaustive survey is beyond the scope of this contribution. I focus here on income and education; for surveys of effects on other socio-economic outcomes, see the individual papers in [5] and [6]. Below I discuss each strand briefly, but I begin with what I think are the general lessons and results. First, the general insight about omitted variable bias likely overstating the impact of a teen birth has been validated across all of the newer research approaches. It is fair to say that most economists working in this research area now accept the idea that the negative causal impact of a teen birth for the women who actually have a birth is modest in magnitude. Teen mothers may be doing poorly, but the teen birth is far from the sole cause. Of course, because the births in question occurred several decades ago, this literature tells us that the impacts were modest, not that they are currently modest. Second, the impacts may have become more negative, a result that is consistent with a trend toward a less generous safety net and a less hospitable labor market for less-skilled and less-educated

5 Technically, the miscarriage approach is also an IV model, but it is easier to understand it by treating it as a natural experiment. 
workers. Third, the results are more fragile than is widely understood. This is, in my opinion, especially true for the miscarriage natural experiment literature, which is the source of the occasional positive effects, but also for the sister studies. The cost of reducing omitted variable bias can be reliance on a sample that is relatively small or specialized and potentially less representative. A quick survey follows.

Sisters. Geronimus and Korenman [16,17] were the first to use this approach in this context. They estimated teen birth effects for pairs of sisters in three nationally-representative data sets and Hoffman, Foster, and Furstenberg [18,19] independently re-examined one of the data sets. The analyses are based on teen births in the 1960s (one data set) and 1970s and early 1980s (the other two). ${ }^{6}$ For the teen sisters from the 1960 s, Geronimus and Korenman found not only that the effects were smaller than in a standard analysis, but that the sister who had a teen birth did no worse, on average, on most economic measures than her sister who had a later birth. She completed about as much education, had a standard of living that was no lower, and was no more likely to be poor. Geronimus went on to argue on the basis of these findings and other health-related findings that early childbearing might be desirable in some disadvantaged subpopulations [20].

The other analyses from both sets of researchers found teen birth effects that were quite consistently negative, although less than in previous research, precisely as an omitted variable analysis would suggest. The average difference in economic well-being between a teen mother and her (non-teen mother) sister was about one-third, whereas in earlier studies, the impact was typically between 40 and $50 \%$. There were also reasonably big differences between the sisters in the probability of being poor, receiving welfare, and educational attainment, all to the detriment of the sister who had the teen birth. The likely explanation for the difference between the results from the various data sets is that the births in the earlier study were far more likely to be marital and that the early period sample suffered from technical sampling problems that made it potentially unrepresentative of sister pairs. ${ }^{7}$

The cost of focusing exclusively on sisters is sample size and representativeness. The results for the earliest dataset are based on samples of about 40-50 sister-pairs with differing teen fertility and even the later stronger results have samples of not more than about 100-150. Larger families are over-represented relative to smaller ones. The research, especially the original paper by Geronimus and Korenman [16], is most important for vigorously making the argument that the problems of teen mothers could lie elsewhere than in their early fertility and for offering an attractive, if limited, methodological approach.

Miscarriage. Because a miscarriage is usually a random event reflecting fetal stress, Hotz, McElroy, and Sanders [15] argued that it could be used as a natural experiment to quantify the effects of a teen birth on the mother. Remarkably, the National Longitudinal Survey of Youth 1979 included a retrospective pregnancy outcome history for teens that included abortion, miscarriage, and even stillbirth as potential classifications. This study is distinctive in several ways. First, it examined the

6 The data sets are the National Longitudinal Survey of Young Women (NLSYW), the Panel Study of Income Dynamics (PSID), and the National Longitudinal Survey of Youth (NLSY79). The NLSYW includes teen births from the 1960s, while the other two include births from the 1970s and early 1980s.

7 In the earlier survey (NLSYW), sisters could be identified only if they were still in their parents' home. Because the sample included women age 14-24 and in light of the early median age at marriage for women in the 1960s, it is likely that many older sisters with marital births were missed. This age sampling issue did not arise in the other data sets. 
impact of births to teens whose pregnancies occurred at age 17 or younger rather than through age 19, as in the usual definition of a teen birth, and second, it followed the sample through their early 30s. This allowed the researchers to distinguish between short-run and longer-run impacts, which is an important difference not fully considered in previous research. The researchers found that the initial negative effects of a teen birth were short-lived. The teen mothers rebounded and by their late-20s did better over a wide range of outcomes than their counterparts who had a miscarriage. The teen mothers were less likely to have graduated from high school, but they were more likely to have received a GED by an essentially offsetting amount. Teen mothers worked more and earned more than their counterparts, and their spouses had higher incomes. Differences in income from welfare between the two groups were very small. The teen mothers were worse off only on two outcomes: they had more births by age 30 and they spent more time as a single mother than did the teens with miscarriages. The authors concluded, that "the failure to account for selection bias vastly overstates (emphasis in original) the negative consequences of teenage childbearing and [the findings] certainly provide no support for the view that there are large negative consequences of teenage childbearing per se for the socioeconomic attainment of teen mothers" [15] (p. 81). So this study suggested that other factors were the primary cause of the poorer outcomes for teen mothers.

Even though this study is careful and thoughtful, it has some weaknesses. First, it is very difficult to obtain reliable information on teen miscarriages from survey data and it is clear that miscarriages were substantially underreported. The entire sample of miscarriages is 68 cases, of which an astonishing $12 \%$ are actually stillbirths. ${ }^{8}$ If misreporting was highest among young women who viewed their early pregnancy as an unfortunate error and who went on to do relatively well, then the sample of women who reported a teen miscarriage would be more disadvantaged than the population of women who had a teen miscarriage. This would bias the analysis toward finding no effect of a teen birth. Second, the miscarriage may not have been sufficient to delay a teen birth: almost a third of the women with a teen miscarriage actually had a subsequent pregnancy by age 17 that resulted in a birth. Third, a reanalysis and extension of the original paper in Hoffman and Maynard [6] found that the same approach applied to more recent teen mothers yielded much more negative impacts of a teen birth across a range of outcomes including educational attainment, own earnings, and the earnings of a spouse. This is another example of the point made earlier: research can only reveal what the effects have been, not what they are or will be, and the longer the time frame of the analysis, the greater the possible difference.

Multiple Methods. Finally, a very interesting recent study by Kane et al. [22] used a range of research methods with a single high-quality data set (ADD-HEALTH), thereby eliminating data set and time period as sources of differing estimates. They focused exclusively on educational attainment. The methods employed include standard regression with reasonably extensive explanatory variables, a related technique called propensity scoring, and several instrumental variables methods including one that is quite sophisticated and involves allowing for the existence of unobserved types of women with

8 In national data from the National Center for Health Statistics [21] miscarriages outnumber stillbirths by a factor of $35: 1$. In the NLSY79 data, the ratio is $7: 1$. If the birth figure is correct, the number of miscarriages ought to be at least twice as high as the number reported. 
different underlying preferences for a teen birth. ${ }^{9}$ Three of the methods yield estimates of a teen birth effect that ranges from 0.7-1.0 fewer years of education, while one method yields an estimate about twice as large. Their preferred estimate is -0.7 , which is a reasonably sizeable impact, but lower than standard regression estimates (about one year in their model) and lower than the overall difference between teen mothers and all other women (about two years). As such, it is consistent with a meaningful negative impact of a teen birth, but also with the general effect of omitted variable bias. They conclude that the wide range of estimates in the literature reflects primarily the different research methods applied.

\section{The Socio-Economic Causes of a Teen Birth: The Opportunity Cost Hypothesis}

Economists love to talk about opportunity cost almost as much as applied economists love to talk about omitted variable bias. Opportunity cost is among the first concepts that students learn in a principles of economics class. It is the cost of an action in terms of what is given up in taking that action, so, for example, it is not the monetary cost of a purchase, but the value of the next most preferred item the same amount of money could have been used to acquire. It applies quite directly and comfortably to teen births. The opportunity cost of having a teen birth is the value of what is given up in alternative options and outcomes over the rest of an individual's lifetime. That value is best thought of as a measure of net lifetime happiness, involving fertility, marriage, work and all the other components of adult life. So the net cost of a teen birth is the difference between the happiness value of the life likely to be had with a teen birth and the happiness value of the likely best alternative life that could have been had if the birth had been delayed. ${ }^{10}$

Economists typically assume that people choose their most preferred feasible alternative, an assumption often denoted as "rational choice" or, in this context, "utility maximization." The hypothesis that follows naturally then is that perhaps teens are rational actors and that some choose not to have a birth and others choose to have a birth because it is their own best personal alternative. This, in a nutshell, is the opportunity cost hypothesis: teen births will be more common when and where and for whom the opportunity cost is low. There are, to be sure, many fragile steps in such an argument, involving knowledge, foresight, planning, and so on, all of which are potentially deficient in matters related to teens in general and teen sexual activity in particular. But it is, at least, an operational and testable hypothesis and, as such, it has been the backbone of research in economics and of policy prescriptions involving the welfare system and safety net. ${ }^{11}$

In practice, economists and policy-makers trying to operationalize the opportunity costs of a teen birth have emphasized likely incomes, especially those from work, marriage, and/or the welfare system. Family well-being is, on average, positively related to income, so this is a reasonable approach.

9 This involves estimating unobserved heterogeneity of "types" of women using maximum likelihood methods developed by Heckman and Singer [23]. One method not used is sisters, which they report yielded unreliable results.

10 Economists use "utility" to represent what I have called happiness value.

11 It is not economists alone who have imputed rationality to prospective teen mothers. The well-known sociologist Elijah Anderson wrote that "The ghetto teenager sees no future to derail, no hope of a future better than today, hence little to lose by having an out-of-wedlock child" and "middle-class youths take a strong interest in their future and now what a pregnancy can do to derail that future" [24] (p. 76). 
The U.S. welfare system provides income support to low-income single parents and, indeed, many teen mothers do end up receiving welfare. Importantly, these women are likely to be ineligible for welfare if they marry the father of their child, according to the rules governing the welfare system. Welfare benefit levels vary quite widely across states and over time; thus, the opportunity costs will be lower in some times and places than others, thereby providing incentives that differ across time and space. This argument, which is usually associated with more conservative politicians and economists, was prominently made by Charles Murray in his book, Losing Ground [25], and, despite its age, it remains a popular refrain.

William Wilson [26] and many others have emphasized the other side of the issue, namely the very poor marriage prospects of many minority, inner-city women that reflects the declining labor market opportunities and rising incarceration rates [27] of their likely marriage partners - minority, inner-city men. The worse are a woman's future marriage prospects and/or her own future labor market opportunities without a birth, the smaller are her opportunity costs and, thus, the more likely she might be to have a birth. Under some circumstances, the costs might be negative, i.e., it might be beneficial to have a birth if marriage prospects are poor and welfare benefits are sufficiently high.

It is relatively easy to identify circumstances where the net cost of a teen birth is likely to be low and others where it is likely to be high. The low cost configuration would be poor work and marriage alternatives and residence in a time or place with more generous welfare benefits. The high cost configuration would be just the opposite: strong marriage and/or work opportunities and less generous welfare benefits.

The empirical work in this area derives mostly from Murray's contention that the generosity of the welfare system was a primary cause and the research reflects an attempt to do a better job at testing the model than he did. Murray sidestepped the actual hard analytical work by constructing special illustrative cases of welfare use, marriage and work in which the income gains to a teen non-marital birth were substantial. But he never provided any evidence whatsoever either that the special cases were representative or that the prospective teen mothers acted on the incentives as he identified them.

Despite all the attention given to the possible role of the welfare system as a responsible factor, the evidence consistently suggests it has a weak effect. In 2013, the teen fertility rate ranged from less than 15 births per 1000 teen girls in five U.S. states to more than 40 births per 1000 in six states, while monthly cash welfare benefits available for a family of two persons through the primary U.S. cash assistance program Temporary Assistance for Needy Families (TANF) ranged from under \$200 in five states to over $\$ 550$ in another five (plus Alaska). But the states with low teen fertility rates are not those with low TANF benefits; in fact, it is quite the opposite. Figure 2 shows the bivariate relationship in 2012 between a state's teen fertility rate and its maximum TANF benefits for a two-person family. As is evident, the relationship is actually negative; on average, the teen fertility rate falls by three births per 1000 for every $\$ 100$ increase in TANF benefits. 2012 is not unusual in any way; a parallel analysis for 2002 or 1992 would yield a very similar relationship.

Just as in the discussion of the consequences of a teen birth, this simple analysis also likely suffers from omitted variable bias. It is certainly not a valid test of the opportunity cost hypothesis, because it only measures the benefits on one side of the comparison, namely, the welfare benefits that would be potentially available. But the opportunity cost hypothesis involves a comparison of benefits along the two teen fertility paths; perhaps young women in states with low welfare benefits have 
correspondingly poor non-welfare opportunities. To test the opportunity cost hypothesis more fully requires constructing reasonable estimates of the income flows along the two teen fertility paths.

It doesn't take much thought to realize that a researcher is in a ticklish situation, because only the outcome that is actually chosen by a particular woman is observable in any data set. For women who are teen mothers, a researcher has no information on the life they could have had if they had not had a teen birth. And the same applies to the women who do not have a teen birth: the "counterfactual" of life with a teen birth is not observed. Not observing the counterfactual state isn't necessarily fatal to this line of research inquiry, if it is possible to estimate what it might have been. And that is a less daunting task than might be assumed. The first research to do this is Duncan and Hoffman [2] and Lundberg and Plotnick [28] took a related approach. The underlying idea is to use actual outcomes for women with no teen birth to impute likely counter-factual outcomes to observationally-similar women who had a birth. ${ }^{12}$ Here, observationally similar means that the two groups of women have similar family backgrounds. Since teen mothers and others may well differ in terms of unobservable factors, too - this was, after all, the core message of the analysis of the consequences of a teen birth - the analyses adjust for selection bias, which was the state-of-the-art statistical procedure for this kind of problem in that time period. It is far from a perfect procedure, but serviceable.

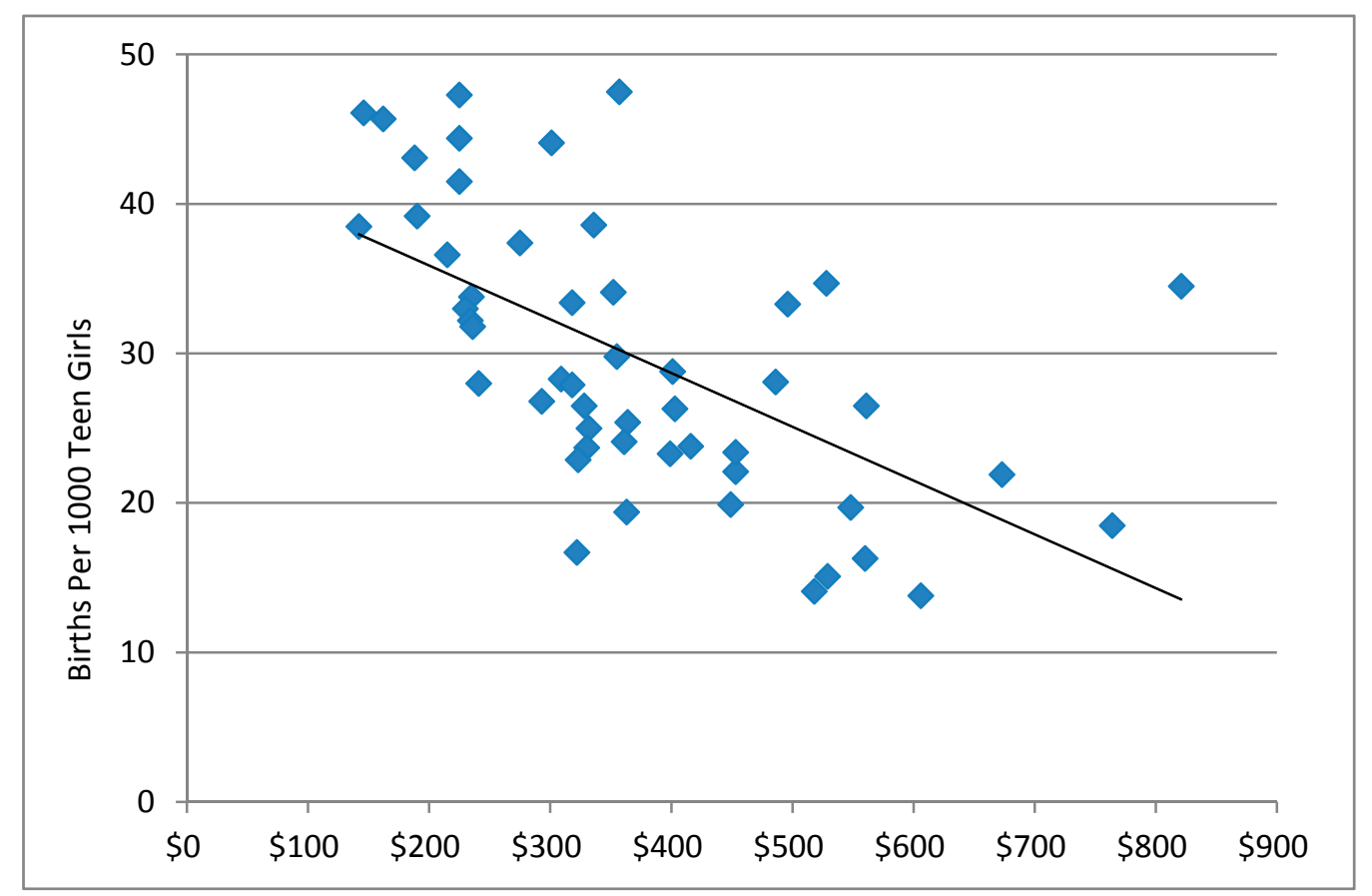

Figure 2. Teen Fertility Rate by U.S. State and Maximum TANF Benefits, Family of Two, 2012.

Duncan and Hoffman applied this procedure to a sample of black teens who had births in the late 1970s and early 1980s. For teen mothers, opportunity costs were measured as the predicted income they might plausibly have about a decade later, when they were in their mid-20s, based on actual

12 Technically, this involves estimating a regression equation of the form $\mathrm{Y}=\mathrm{X} \beta+\mu$ for women who did not have a teen birth, where $\mathrm{Y}$ is some outcome of interest and $\mathrm{X}$ represents determinants of $\mathrm{Y}$ that are observed both for women who did not have a teen birth and women who had one. The estimated values of $\beta$ are the effect of $X$ on $Y$. The predicted outcome for a woman with a teen birth is the product of her own value of $\mathrm{X}$ and the estimated value of $\beta$. 
observed incomes of similar women who did not have a teen birth. For women who did not have a birth, the counterfactual income was the welfare income they would be eligible for in their state of residence. Lundberg and Plotnick looked at teen births that occurred mostly in the early 1980s. They focused less directly on the counterfactual income for teens, but did examine welfare benefits and other policies (abortion funding and legal environment) in a multivariate context that also included multiple measures of a young woman's socio-economic background. Note that both of these studies reflect teen birth behavior at a time when the teen fertility rate was more than twice as high as it is in the mid-2010s.

Both studies find no evidence that the level of welfare benefits was a determinant of a teen birth for black women; Lundberg and Plotnick find that welfare benefits did increase the probability of a teen birth for whites. Duncan and Hoffman found that teens with better non-birth opportunities were more likely to delay their first birth beyond their teen years. But the impact was relatively modest: a $25 \%$ increase in opportunity cost decreased the proportion with a teen birth by about $9 \%$.

With the kind of data that is available, these studies, old as they are, are about as good as can be executed. Economists can interpret these results as suggesting that benefits and costs have some influence on teen fertility behavior, but it is hard to argue that the effects of these measures of benefits and costs are large from a policy perspective. But in a related literature, two very interesting recent papers tell us how and why opportunity costs might sometimes matter less than they could and how and why they might matter more. I think these papers provide clues to the final issue on my agenda, namely the recent sharp decline in teen fertility and its likely future trend.

New Directions. Research by economists Melissa Kearney and Philip Levine [29] suggests that income inequality may play an important role in teen fertility. Rising income inequality is one of the most significant labor market developments of the past few decades; an accessible summary is in Autor [30]. Their argument is a variant of the opportunity cost model. They hypothesize that more extreme inequality creates greater feelings of economic hopelessness, leading young women to view opportunity costs as very low. When the distance to the middle class is greater and more difficult to traverse, they argue, perhaps young women conclude that they won't make it there, no matter what they do, so they have little to lose by having a teen birth. ${ }^{13}$

Kearney and Levine examined the relationship between teen births and "lower tail inequality," across U.S. states; lower tail inequality is defined as the ratio of household income at the median to income at the 10th percentile of the distribution and thus roughly measures distance from near the bottom to the middle class. The critical comparison in their analysis is between the teen fertility of young women from poorer households (measured by low parental education) in high inequality states with the behavior of similar young women in lower inequality states. When they divide states into three broad categories by the extent of inequality, they find a clear pattern. In the low inequality states, about $15 \%$ of teens from households where the mother was not a high school graduate had a birth. In states with medium inequality, the percentage with a birth was about three percentage points higher and in states with high income inequality, it was another five points higher. The overall difference between the low and high inequality states is about seven percentage points, which is almost a $50 \%$

13 In this approach, income inequality and income immobility are being used somewhat interchangeably. Inequality is a greater issue if income positions are relatively immobile. 
difference. The differences in teen birth rates are much smaller across the three groups of states for young women whose mother was a high school graduate and the differences disappear entirely for women whose mother attended college. This suggests that the differences are not due to something about the states themselves.

Kearney and Levine confirm this relationship in more elaborate regression analysis of teen fertility that controls for other individual and state characteristics. They find that a one percentage point increase in lower tail inequality, which is approximately the difference between low and high inequality states, increases the proportion with a teen birth by 5.3 percentage points for teens whose mother was not a high school graduate and by 2.1 percentage points for teens whose mother was a high school graduate. They show that other measures of income and income inequality, including upper-tail inequality and average income at the 10th and 50th percentiles, all have much weaker effects on teen births. The impact of lower tail inequality is not much affected by controlling for other state characteristics, such as religiosity, the political leaning of the state, or its minority population. So this paper is an important clue about how opportunity costs may be perceived.

In another study, Kearney and Levine [31] examined the influence of the media on teen fertility. ${ }^{14}$ It is easy enough to believe that television and movies might influence broad cultural attitudes about teen motherhood, but it is hard to actually measure the impact, whether positive or negative. Kearney and Levine managed to do that, focusing on the impact of MTV's 16 and Pregnant series, which aired beginning in 2009. The show was a popular hour-long documentary series that followed a teen mother through much of her pregnancy, portraying much of it in a gritty and very unglamorous light. Kearney and Levine write that "realities of the lives of teen mothers are presented in ways that may have been unknown or difficult to imagine for other teens viewing the show" (p. 8). In economists' jargon, the show plausibly increased a teen's perception of the opportunity costs of a teen birth, especially its short-term impact on daily life.

To measure the causal impact of 16 and Pregnant, Kearney and Levine took advantage of a natural experiment, this time involving geographic variation in MTV viewership across TV markets in the months prior to the airing of 16 and Pregnant. They used viewership in an earlier time period rather than actual viewership of the program because actual viewership might well be higher in areas where teen births were more common, thereby creating a spurious positive relationship between viewership and teen fertility. The impact of the programs on teen social media behavior is evident. Google searches and Twitter messages about 16 and Pregnant jumped sharply immediately following each episode, by approximately 30\%-40\%. More importantly, Google searches and tweets containing the terms "birth control" and "abortion" also both increased following the airing of each episode and they increased more in geographic areas where searches and tweets about 16 and Pregnant increased more.

Most importantly, Kearney and Levine find that the program appeared to affect teen fertility rates. Teen birth rates fell more in areas that had higher MTV viewership and, thus, where more teens were (exogenously) exposed to the show. They estimate that 16 and Pregnant and the Teen Mom shows that followed it led to a $6 \%$ reduction in the number of teen births that were conceived after the show began through the end of 2010. This is about one-third of the total decline in teen fertility during this time period.

14 Other research papers looking at the impact of the media on fertility include [32] and [33]. 
Together, the two papers suggest a subtle reinterpretation of the opportunity cost hypothesis. Perhaps opportunity costs don't matter as much as economists would like them to because teens have a highly erroneous faulty conception of them, in particular, a conception that is consistently and systematically too small.

\section{What We've Learned: Economics and Teen Fertility}

There was a time, not so very long ago, when researchers confidently believed, first, that a teen birth was an economic catastrophe and then somewhat later, that it might be primarily or even exclusively a marker for disadvantage, rather than an important independent causal factor. As I have argued, the latter is, in its weaker form, a thoroughly plausible hypothesis and likely correct. The evidence for the strong version rests largely on the results of one approach (miscarriages), which, while methodologically appealing, suffers from substantial data challenges and may well reflect the opportunities available in an economic environment more hospitable to less educated persons than the current and future ones are likely to be. I think in the end we have come to a reasonable place, one that appropriately appreciates both the selective features of the young women who become teen mothers and the causal effect of a teen birth. This result tells us something very important: to really make a difference in the lives of prospective teen mothers, we need to help them delay a birth and address at least some of the other deficits in their lives. It is also very important to appreciate that the correct estimate of a teen birth effect to use in the evaluation of a teen birth intervention depends very much on what that intervention actually does. It can be far greater than the causal estimate, which may hold constant things that are changed by the policy intervention.

There was also a time, also not so very long ago, when the U.S. teen fertility rate was sky-high and when some argued that this was an optimal behavioral response to low opportunity costs. But since then, teen fertility has declined so steadily and sharply that either the opportunity costs must have increased dramatically or the original hypothesis of optimal behavior must have been incorrect. Like most complicated social phenomena, the answer is not likely to be one or the other exclusively. It is likely that opportunity costs of a teen birth have increased. Reform of the welfare system that imposed lifetime receipt limits and instituted serious work requirements probably played some role, as did the general deterioration of labor markets for less-educated workers. Both contributed to making life following a teen birth a less attractive option. But the findings of Kearney and Levine about the effect of MTV suggest that, however difficult it is to believe, teens knew relatively little about the immediate reality of pregnancy. Their findings about the role of inequality suggest that where inequality is greater, teens at risk of a teen birth tended to understate its long-run costs by underestimating their own prospects. For a broad discussion of factors affecting the recent decline in U.S. teen fertility, see [34].

Like any good lasting relationship, the research love affair between economics and teen fertility has been valuable for both partners. An economic perspective has contributed meaningfully to the understanding of both the causes and consequences of a teen birth, even if it has not managed to definitely resolve either analysis. The analytical problems are very hard ones, beset with a wide range of research challenges, many of which I have touched on here. Perhaps most importantly, the economics research showed that the strongest statements about the negative socio-economic consequences of a teen birth and about the causal effect of the welfare system on a teen birth were both 
exaggerated. Where economists have erred, it has been primarily by failing to appreciate the fragility of their analyses and drawing conclusions that were stronger than the results warranted. Symmetrically, the relationship has also been beneficial to economics, forcing it to confront the limitations of rational choice modeling and the difficulties of applied research. The new work of Kearney and Levine absolutely reflects that, as does, for example, the work of Yakusheva and Fletcher [35] on the impact of a peer's pregnancy on the likelihood of a teen birth.

I predict with substantial confidence that this research relationship will continue and thrive, especially as economists expand their tool kit. With a bit less confidence, I predict that the downward trend in teen fertility will continue, perhaps not at its current rate of decline, but still on a downward trajectory. And that tells us something important about how young women, even women from disadvantaged families and neighborhoods, view their futures. We need to use the new advances in contraceptive technology, especially LARCs, to enable young women to make the decisions that are in their long-run interest. And we need to do more than that, as well, to make the alternatives economically more attractive. And in doing that, our focus may need to be wider, including, for example, efforts to improve the economic position of young less-educated men and women.

\section{Acknowledgment}

The author acknowledges the constructive comments of two anonymous referees.

\section{Conflicts of Interests}

The author declares no conflict of interest.

\section{References}

1. Campbell, A.A. The role of family planning in the reduction of poverty. J Marriage Fam. 1968, 30, 236-245.

2. Duncan, G.J.; Hoffman, S.D. Welfare benefits, economic opportunities, and out-of-wedlock births among black teenage girls. Demography 1990, 27, 519-535.

3. Hamilton, B.; Martin, J.; Osterman, M.; Curtin, S. Births: Preliminary data for 2014. Natl. Vital Stat. Rep. 2015, 64, 1-18.

4. Hofferth, S.L.; Hayes, C.D. (Eds.) Risking the Future: Adolescent Sexuality, Pregnancy, and Childbearing; National Academy Press: Washington, DC, USA, 1987.

5. Maynard, R.A. (Ed.) Kids Having Kids: Economic Costs and Social Consequences of Teen Pregnancy; Urban Institute Press: Washington, DC, USA; Lanham, MD, USA, 1997.

6. Hoffman, S.D.; Maynard, R.A. (Eds.) Kids Having Kids: Economic Costs and Social Consequences of Teen Pregnancy, 2nd ed.; Urban Institute Press: Washington, DC, USA, 2008.

7. Heckman, J.J. Sample selection bias as a specification error. Econometrica 1979, 47, 153-161.

8. Peipert, J.F.; Madden, T.; Allsworth, J.E.; Secura, G.M. Preventing unintended pregnancies by providing no-cost contraception. Obstet. Gynecol. 2012, 120, 1291-1297. 
9. Secura, G.M.; Madden, T.; McNicholas, C.; Mullersman, J.; Buckel, C.M.; Zhao, Q.; Peipert, J.F. Provision of no-cost, long-acting contraception and teenage pregnancy. N. Engl. J. Med. 2014, 371, 1316-1323.

10. Ashenfelter, O.; Krueger, A. Estimates of the economic return to schooling from a new sample of twins. Am. Econ. Rev. 1994, 84, 1157-1173.

11. Plotnick, R.D.; Hoffman, S.D. The effect of neighborhood characteristics on young adult outcomes: Alternative estimates. Soc. Sci. Q. 1999, 80, 1-18.

12. Goldin, C.; Olivetti, C. Shocking labor supply: A reassessment of the role of World War II on women's labor supply. Am. Econ. Rev. 2013, 103, 257-262.

13. Goldin, C.; Katz, L.F. The power of the Pill: Oral contraceptives and women's career and marriage decisions. J. Pol. Econ. 2002, 110, 730-770.

14. Card, D.; Krueger, A.B. Minimum wages and employment: A case study of the fast-food industry in New Jersey and Pennsylvania. Am. Econ. Rev. 1994, 84, 772-793.

15. Hotz, V.J.; McElroy, S.W.; Sanders, S.G. The impacts of teenage childbearing on the mothers and the consequences of those impacts for government. In Kids Having Kids; Maynard, R., Ed.; The Urban Institute Press: Washington, DC, USA, 1997.

16. Geronimus, A.T.; Korenman, S.D. The socioeconomic consequences of teen childbearing reconsidered. Q. J. Econ. 1992, 107, 1187-1214.

17. Geronimus, A.T.; Korenman, S.D. The socioeconomic costs of teenage childbearing: Evidence and interpretation. Demography 1993, 30, 281-290.

18. Hoffman, S.D.; Foster, E.M.; Furstenberg, F.F., Jr. Reevaluating the costs of teenage childbearing. Demography 1993, 30, 1-13.

19. Hoffman, S.D.; Foster, E.M.; Furstenberg, F.F., Jr. Reevaluating the costs of teenage childbearing: Response to Geronimus and Korenman. Demography 1993, 30, 291-296.

20. Geronimus, A.T. The weathering hypothesis and the health of African American women and infants. Ethn. Dis. 1992, 2, 207-221.

21. Hoyert, D.L. Medical and life-style risk factors affecting fetal mortality, 1989-90. Vital Health Stat. 1996, 31, 1-32.

22. Kane, J.B.; Morgan, S.P.; Harris, K.M.; Guilkey, D.K. The educational consequences of teen childbearing. Demography 2013, 50, 2129-2150.

23. Heckman, J.J.; Singer, B. A method for minimizing the impact of distributional assumptions in econometric models for duration data. Econometrica 1984, 52, 271-320.

24. Anderson, E. Sex codes and family life among poor inner city youth. Ann. Am. Acad. Polit. Soc. Sci. 1989, 501, 59-78.

25. Murray, C.A. Losing Ground: American Social Policy, 1950-1980; Basic Books: New York, NY, USA, 1984.

26. Wilson, W.J. The Truly Disadvantaged: The Inner City, the Underclass, and Public Policy; University of Chicago Press: Chicago, IL, USA, 1987.

27. Charles, K.K.; Luoh, M. Male incarceration, the marriage market, and female outcomes. Rev. Econ. Stat.2010, 92, 614-627.

28. Lundberg, S.; Plotnick, R.D. Adolescent premarital childbearing: Do economic incentives matter? J. Labor Econ. 1995, 13, 177-200. 
29. Kearney, M.S.; Levine, P.B. Income inequality and early non-marital childbearing. J. Hum. Res. 2014, 49, 1-31.

30. Autor, D.H. Skills, education, and the rise of earnings inequality among the other "99 percent". Science 2014, 344, 843-851.

31. Kearney, M.S.; Levine, P.B. Media Influences on Social Outcomes: The Impact of MTV's 16 and Pregnant on Teen Childbearing; National Bureau of Economic Research Working Paper 19795; National Bureau of Economic Research: Cambridge, MA, USA, 2014.

32. Trudeau, J. The role of new media on teen sexual behaviors and fertility outcomes? The case of 16 and Pregnant. South. Econ. J. 2015, doi:10.1002/soej.12034.

33. Guldi, M.; Herbst, C.M. Offline Effects of Online Connecting: The Impact of Broadband Diffusion on Teen Fertility Decisions; IZA Discussion Paper Series No. 9076; Institute for the Study of Labor: Bonn, Germany, 2015.

34. Kearney, M.S.; Levine, P.B. Investigating recent trends in the U.S. Teen birth rate. J. Health Econ. 2015, 41, 15-29.

35. Yakusheva, O.; Fletcher, J. Learning from teen childbearing experiences of close friends: Evidence using miscarriages as a natural experiment. Rev. Econ. Stat. 2015, 97, 29-43.

(C) 2015 by the author; licensee MDPI, Basel, Switzerland. This article is an open access article distributed under the terms and conditions of the Creative Commons Attribution license (http://creativecommons.org/licenses/by/4.0/). 